rapidly in the cold or warm to give purple or blue products. A variety of steroid drugs, especially those containing a 17 $\alpha$-ethynyl group, give coloured and/or fluorescent products. If conditions are carefully standardized, particular sequences of colour/fluorescence change help to distinguish different groups of steroids. Recommended experimental conditions are described elsewhere (Jeffery, 1971, 1972). The convenience of the techniques is demonstrated for (1) detection of the synthetic oestrogen mestranol [3 - methoxy - 19 - nor - 17 $\alpha$ - pregna - 1,3,5(10) - trien 20-yn-17 $\beta$-ol], (2) distinguishing the products of selective reduction of progesterone (pregn-4-ene3,20-dione) and (3) distinguishing 7-oxopregnenolone (3 $\beta$-hydroxypregn-5-ene-7,20-dione) from common steroids absorbing in the same region of the u.v., e.g. 4-ene-3-ones. These reactions work best on silica-gel layers. Other common staining reagents such as 2,4-dinitrophenylhydrazine and dodecamolybdophosphoric acid can be used after the $\mathrm{HCl}$-vapour procedure.

The interest and encouragement of Professor S. C. Frazer and gifts of steroids from many friends are gratefully acknowledged.

Jeffery, J. (1971) J. Chromatogr. 59, 216

Jeffery, J. (1972) J. Chromatogr. 67, 188

\section{A Method for the Analysis of ${ }^{15} \mathbf{N}$-Labelled Amino Acids in the Effuent from Preparative Amino Acid-Analysis Columns}

By Susan E. Hawkes, Peter J. Buttery and Dyfed LEWIS (Department of Applied Biochemistry and Nutrition, University of Nottingham, Sutton Bonington, Loughborough, Leics. LE12 SRD, U.K.)

Analysis of micromolar quantities of ${ }^{15} \mathrm{~N}$-labelled amino acids in effluents from preparative amino acid systems presents considerable problems. Conventional methods, which require about $70 \mu \mathrm{mol}$ of $\mathrm{N}$ (Anon., 1970), employ the Kjeldahl technique and subsequent conversion of the $\mathrm{NH}_{3}$ produced into $\mathrm{N}_{2}$ gas by using hypobromite before analysis in a mass spectrometer. A technique is reported here employing emission spectrometry (Leickman et al., 1968), which is suitable for quantities as small as $0.5 \mu \mathrm{mol}$ of amino acid contained in large volumes of citric acid buffer.

The fraction, up to $50 \mathrm{ml}$, containing the amino acid is adjusted to $\mathrm{pH} 5.5$ and heated with half its volume of ninhydrin reagent $(1 \mathrm{~g}$ of ninhydrin, $0.15 \mathrm{~g}$ of hydrindantin, $70 \mathrm{ml}$ of 2-methoxyethanol and $30 \mathrm{ml}$ of water) for $15 \mathrm{~min}$ at $100^{\circ} \mathrm{C}$. The diketohydrindylidine-diketohydrindamine, which contains the $\alpha$ amino $\mathbf{N}$ from the amino acid, is then extracted from the citric acid buffer with chloroform. It is essential to adjust the $\mathrm{pH}$ of the solution to 3.3 to facilitate extraction. Below pH3.0 the diketohydrindylidinediketohydrindamine is destroyed (Kennedy, 1965). The chloroform is then evaporated to dryness under reduced pressure in a glass bubble of approx. $5 \mathrm{ml}$ capacity. The bubble is crushed and the powder added to a thick-walled Pyrex-glass tube together with $1.5 \mathrm{~g}$ of $\mathrm{CuO}$ and $1 \mathrm{~g}$ of $\mathrm{CaO}$. The tube is evacuated to a pressure of $0.133 \mathrm{~N} \cdot \mathrm{m}^{-2}\left(10^{-3} \mathrm{Torr}\right)$, sealed and heated at $550^{\circ} \mathrm{C}$ overnight. The ${ }^{15} \mathrm{~N}$ content of the $\mathrm{N}_{2}$ gas produced (Dumas reaction) is determined by emission spectrometry, by using the Dumas tube as an electrodeless discharge tube (Leicknam et al., 1968).

Phenol is not used in the analyser buffers because it is extracted into the chloroform and causes the Dumas tube to explode. It is not possible to use the column effluent directly since the high carbon content gives rise to too much gas within the tube.

During the manipulation of samples a certain amount of contamination is unavoidable; for example the \% atoms excess of $1 \mu \mathrm{mol}$ of amino acid can be underestimated by up to $25 \%$. Preliminary experiments indicate that the contamination can be determined by assay of a $\left[{ }^{15} \mathrm{~N}\right]$ glycine sample of known \% atoms excess with each batch of samples.

S. E. H. holds a Ministry of Agriculture, Fisheries and Food Studentship.

Anon. (1970) Tech. Rep. Ser. Int. At. Energy Ag. 111, 19 Kennedy, I. R. (1965) Anal. Biochem. 11, 105-110

Leicknam, J. P., Middelboe, V. \& Proksch, G. (1968) Anal. Chim. Acta 40, 487-502

\section{Degradation of Sclerotan, a $\beta-(1 \rightarrow 3)-G l u c a n$, by Enzymes from Fungi Parasitic on Sclerotia}

By John S. D. Bacon, A. H. Gordon and D. Jones (Macaulay Institute for Soil Research, Craigiebuckler, Aberdeen AB9 2QJ, U.K.)

The resting bodies, sclerotia, of a number of fungi pathogenic towards plants contain a gel-forming polysaccharide, first found in Sclerotinia libertiana, named 'sclerotan', and shown by Kitahara \& Takeuchi (1961) to be a $\beta-(1 \rightarrow 3)$-linked glucan with single glucose residues attached at intervals by $\beta$ - $(1 \rightarrow 6)$-linkage. Studies of its enzymic degradation and biosynthesis (Johnson et al., 1963; Batra et al., 1969) have emphasized the regularity of its structure.

We have examined the composition of cell walls of several sclerotia-forming plant pathogens (Jones, 1970; Jones et al., 1972). Culture fluids from two fungi parasitic on Sclerotinia sclerotiorum will lyse cell-wall preparations from this species, in which sclerotan is the predominant wall component (Jones \& Watson, 1969). When the culture fluid was fractionated (cf. Bacon et al., 1970) several $\beta-(1 \rightarrow 3)$ glucanases were found, but none would lyse cell walls 